\title{
ㄷำ1
}

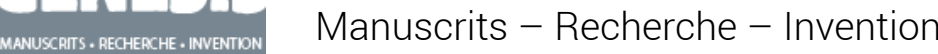

43 | 2016

Bande dessinée

\section{Töpffer, zigzag versus horizon}

\section{Gérald Gorridge}

\section{(2penEdition}

\section{Journals}

Édition électronique

URL : http://journals.openedition.org/genesis/1710

DOI : $10.4000 /$ genesis. 1710

ISSN : 2268-1590

\section{Éditeur :}

Presses universitaires de Paris Sorbonne (PUPS), Société internationale de génétique artistique littéraire et scientifique (SIGALES)

\section{Édition imprimée}

Date de publication : 12 décembre 2016

Pagination : 163-174

ISBN : 9791023105490

ISSN : 1167-5101

\section{Référence électronique}

Gérald Gorridge, «Töpffer, zigzag versus horizon », Genesis [En ligne], 43 | 2016, mis en ligne le 29 novembre 2017, consulté le 02 mai 2019. URL : http://journals.openedition.org/genesis/1710 ; DOI : 10.4000/genesis.1710

Ce document a été généré automatiquement le 2 mai 2019.

Tous droits réservés 


\title{
Töpffer, zigzag versus horizon
}

\author{
Gérald Gorridge
}

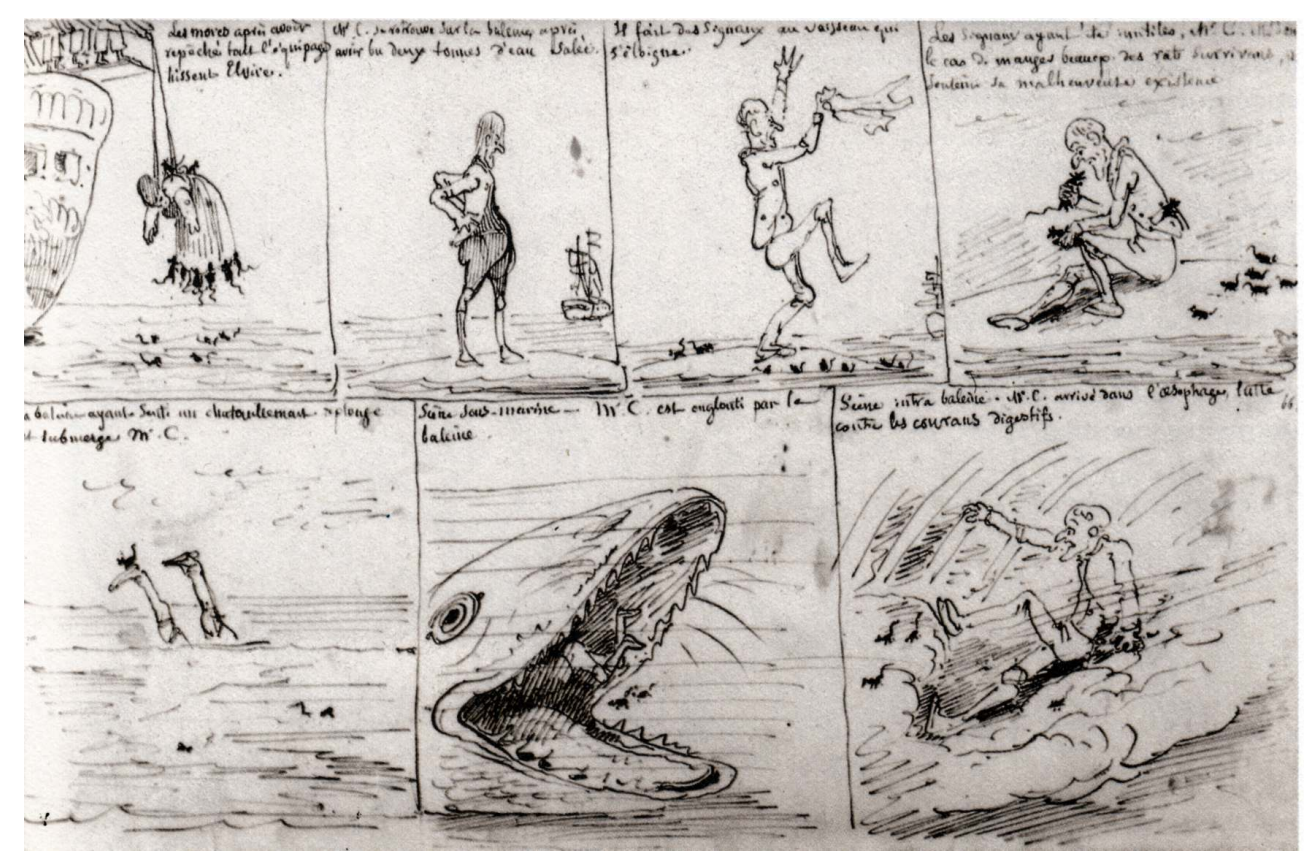

Histoire de Monsieur Cryptogame, première version inédite en carnets, 1830

1 Lorsqu'on se repenche sur ce que Töpffer nommait ses « Histoires en estampes », ce qui frappe d'emblée le lecteur est leur format: oblong ou "à l'italienne », par opposition au format dit «à la française ", c'est-à-dire plus haut que large. Ce dernier format va l'emporter finalement, et très précocement, depuis certains albums de Gustave Doré (comme Trois Artistes incompris et mécontents, 1851 ou Histoire pittoresque, dramatique et caricaturale de la Sainte Russie, 1854) ou bien encore les albums de Cham. Ce format continue de dominer chez la très grande majorité de nos albums de bande dessinée contemporains. Les raisons en sont essentiellement pratiques : solidité plus grande de la reliure, encombrement et présentation chez les libraires. Mais il est intéressant d'examiner de plus près les caractéristiques de ce format originel, voulu par Töpffer, tant dans ses carnets de voyages que dans ses histoires en estampes. Pourquoi une telle 
affirmation de l'horizontalité et s'agit-il seulement d'une question formelle ? Cependant, au tout début, Töpffer envisageait une horizontalité moins radicale.

2 Le dispositif des premières "bandes dessinées" composées par Rodolphe Töpffer comportait dans leur version de départ deux rangées d'images par planche. Il a été abandonné au profit d'une seule rangée - que l'on appelle strip aujourd'hui - dans la présentation définitive qui eut par la suite un succès considérable: il s'agit de la «collection des Jabot », du nom du premier d'entre eux paru en 1833, Histoire de Monsieur Jabot, alors même que le premier réalisé, la toute première "bande dessinée ", fut Les Amours de Monsieur Vieux Bois, en 1827, dans une édition originale de quelques centaines d'exemplaires, introuvable aujourd'hui.

Pourquoi Rodolphe Töpffer a-t-il renoncé à cette forme pourtant convaincante de bande dessinée à deux registres superposés? Nous allons tout d'abord commenter brièvement ces premières versions d'histoires en estampes, restées à l'état de brouillons inédits. Puis nous examinerons les carnets de voyage par lesquels le Genevois a commencé dans les années 1820 , et dont quatorze sur vingt-quatre seulement ont été publiés. Enfin nous reviendrons aux histoires en estampes dans leur forme définitive en nous rapprochant de leurs sujets pour comprendre le choix de l'auteur.

\section{Töpffer inventeur de la planche à plusieurs strips}

4 Chronologiquement du point de vue de la création ${ }^{1}$, nous pouvons nous rendre compte ciaprès (fig. 1 à 4) que les deux planches des Amours de Monsieur Vieux Bois reproduites dans leur version initiale inédite de 1827 puis définitive de 1839, semblent perdre quelque chose: moins d'images sur la planche, donc moins d'interaction narrative, abandon de l'utilisation des diagonales en fin de strips le long desquelles le regard peut glisser au début du strip inférieur.

Fig. 1

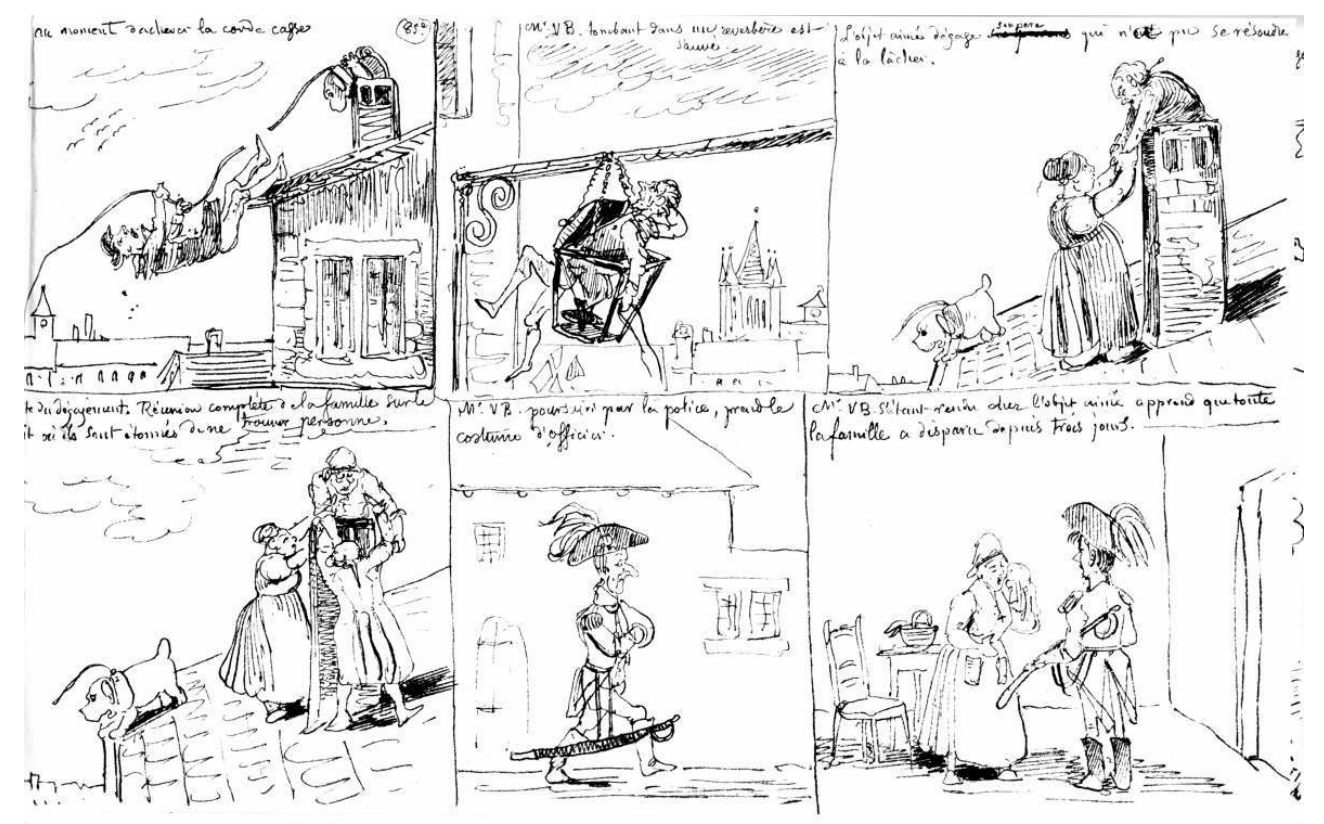


Fig. 2

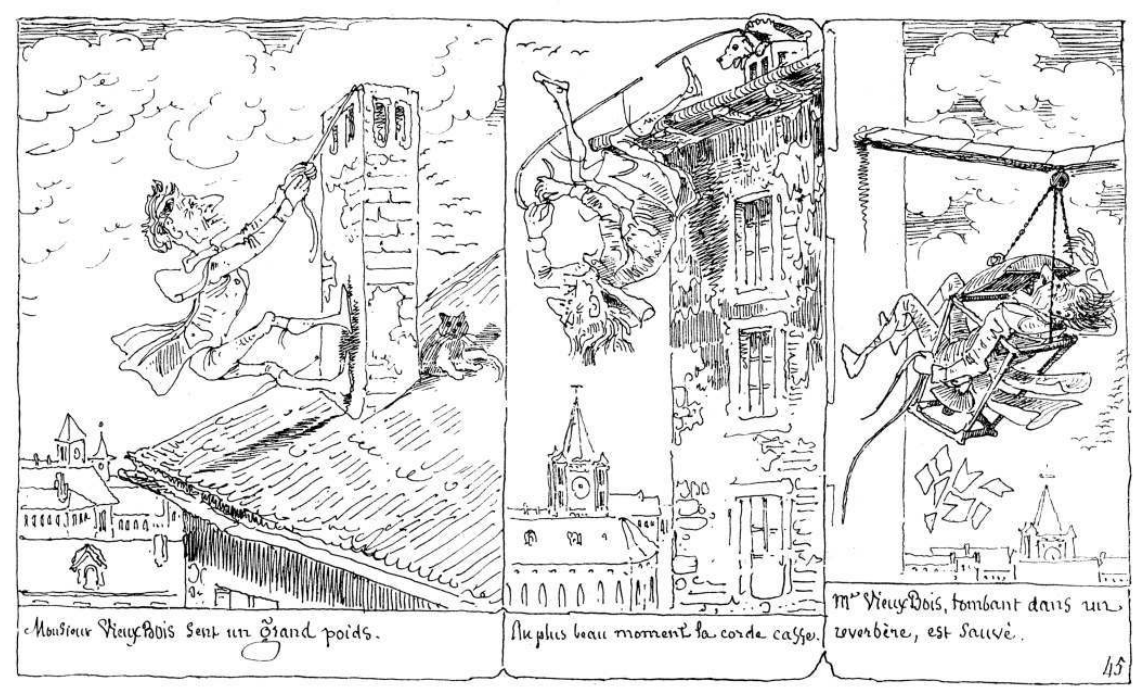

Fig. 1 et 2 : Les Amours de Monsieur Vieux Bois, première version inédite (1827) et version publiée (1839)

Fig. 3

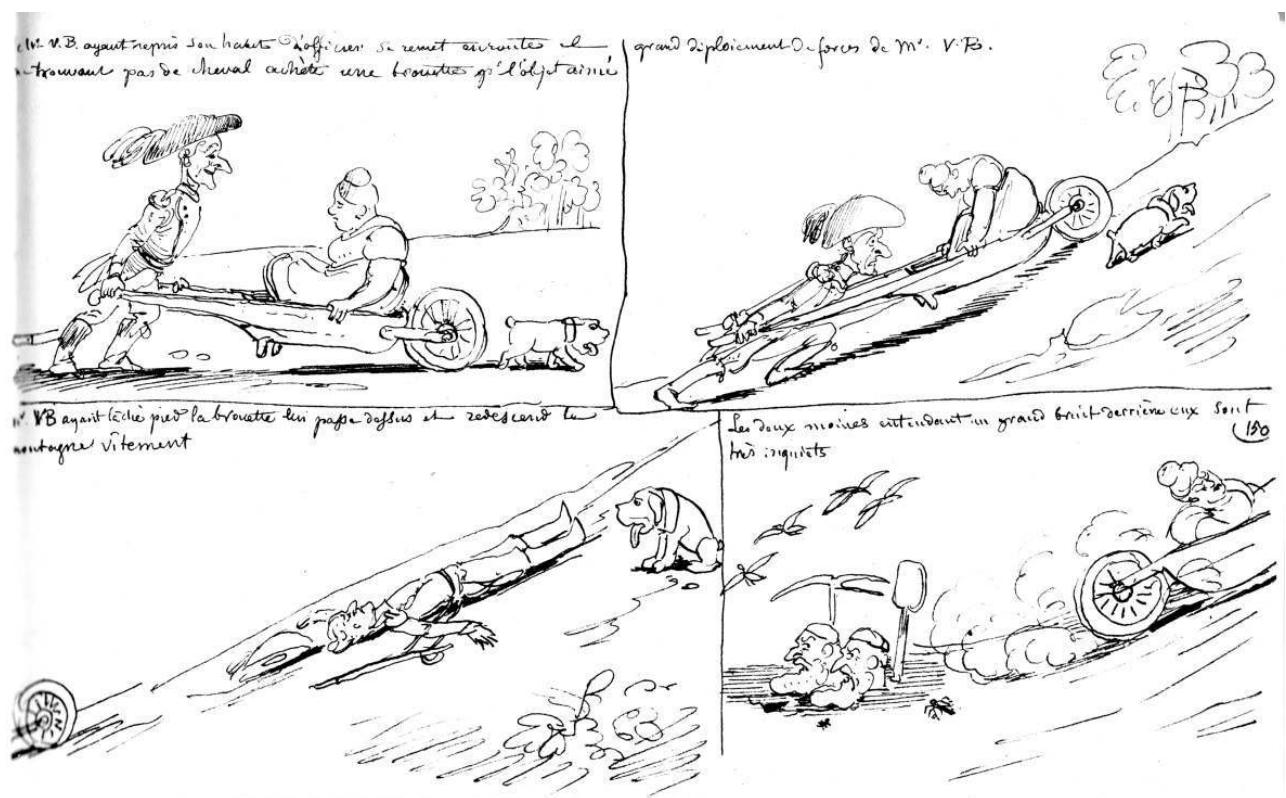




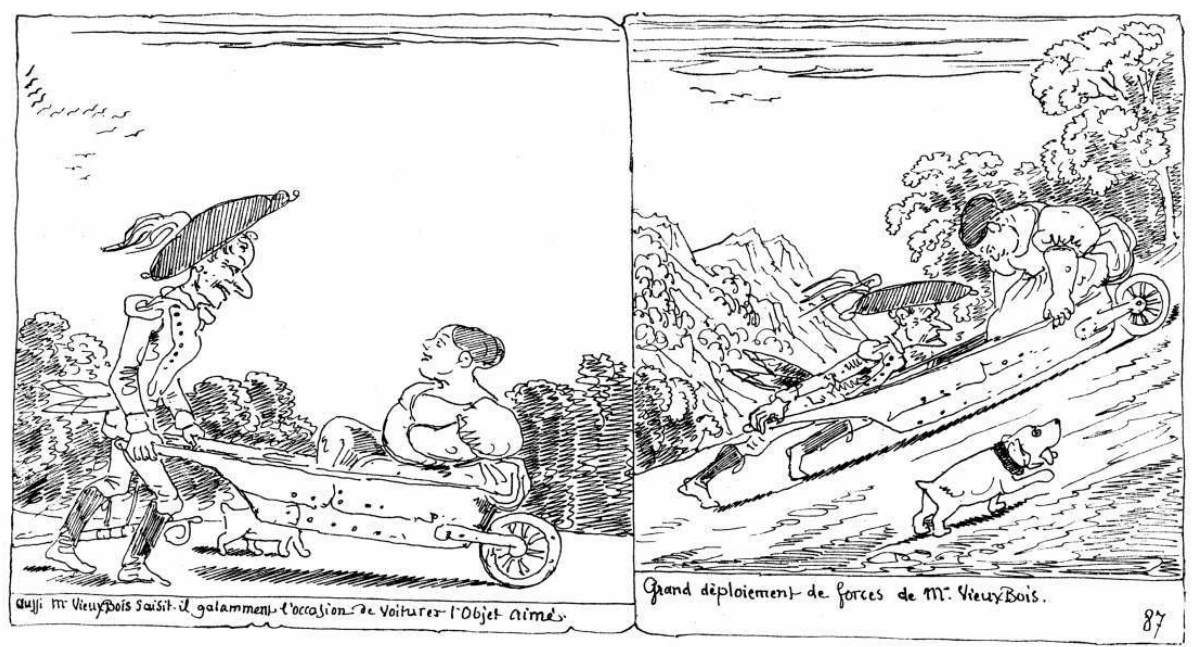

Fig. 3 et 4 : Les Amours de Monsieur Vieux Bois, première version inédite (1827) et version publiée (1839)

De même, l'Histoire de Monsieur Cryptogame jouait, dans sa première approche en 1830, de davantage de variété dans la place du texte (disposé sous l'image finalement, fig. 5 et 6). Et les jeux de densité graphique étaient également beaucoup plus riches. Ce processus d'affadissement apparent se poursuit avec l'interprétation de cham qui omet de retourner les images en les gravant pour L'Illustration en 1845, comme cela a été déjà relevé $^{2}$ : « Le lecteur revient à chaque case sur ses pas » (fig. 7 à 9).

Fig. 5

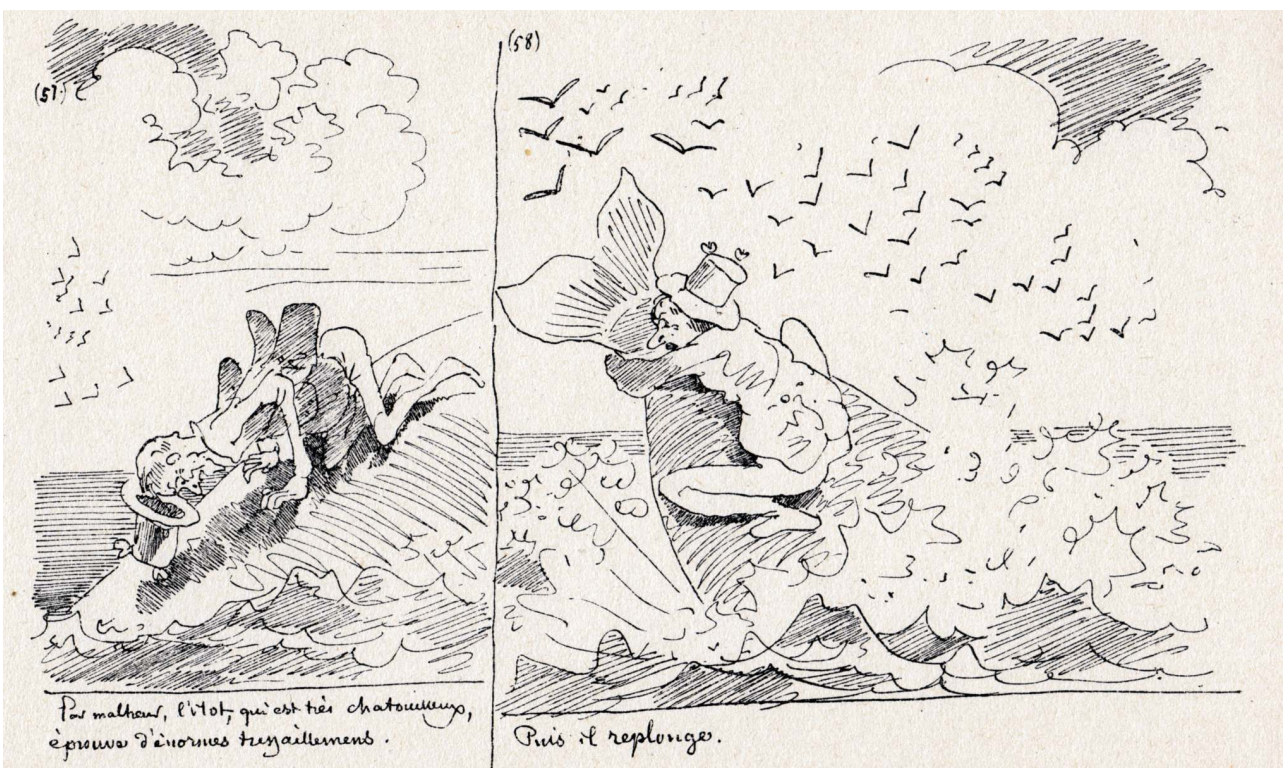


Fig. 6

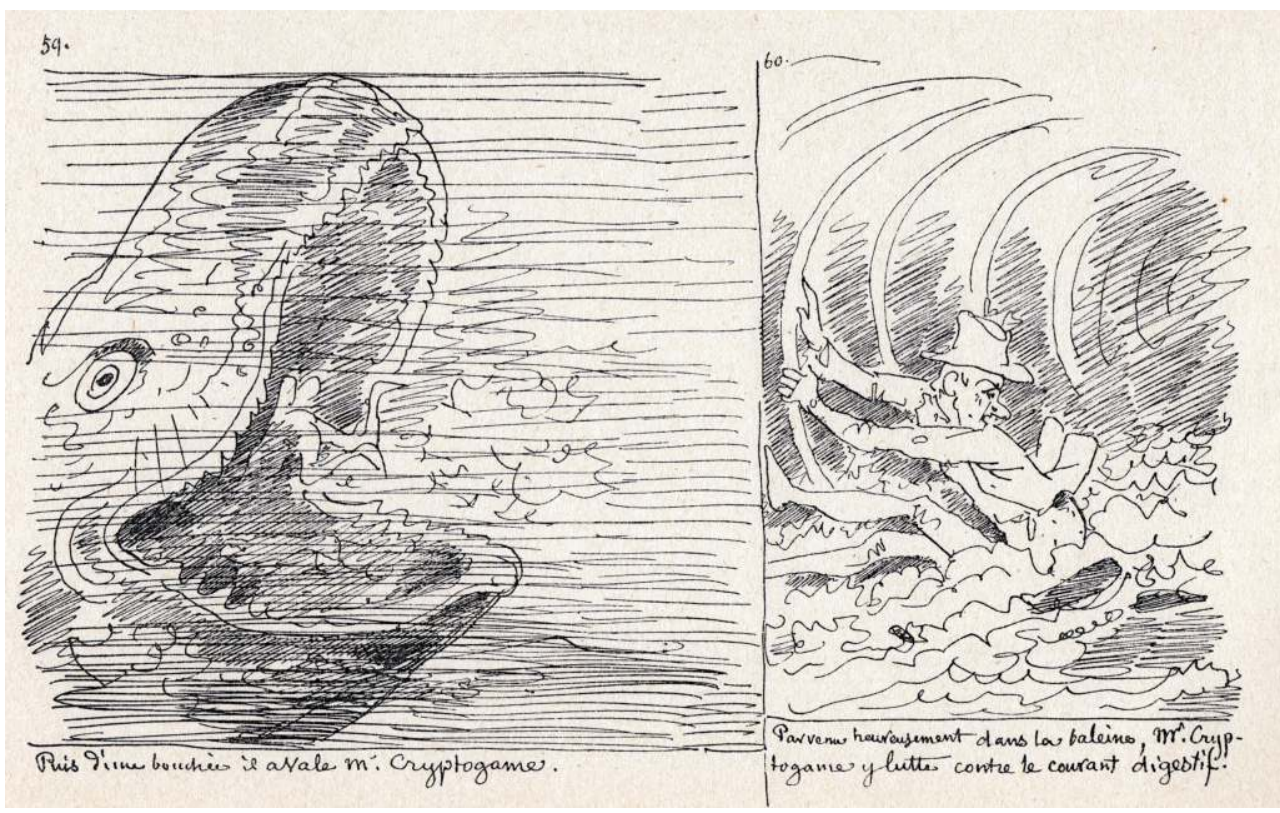

Fig. 5 et 6 : Histoire de Monsieur Cryptogame, deuxième version inédite, 1845

Fig. 7

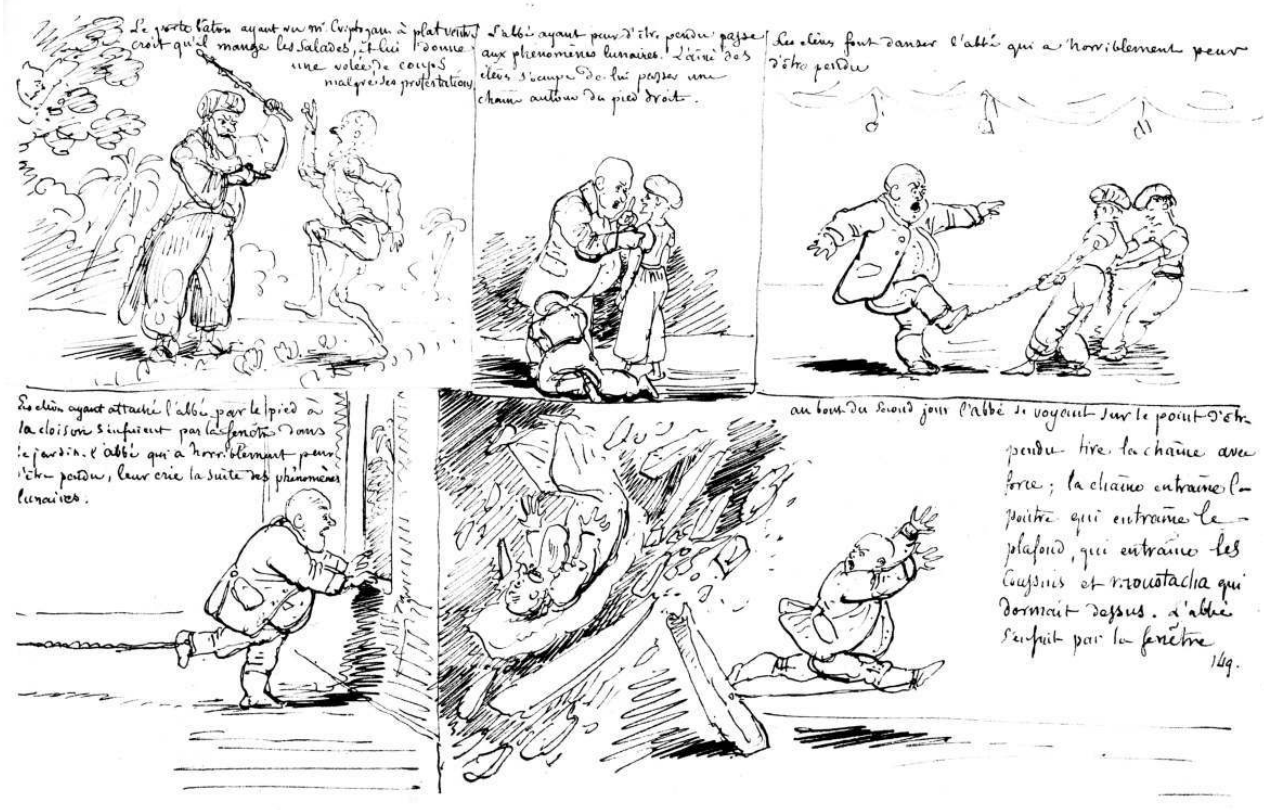


Fig. 8

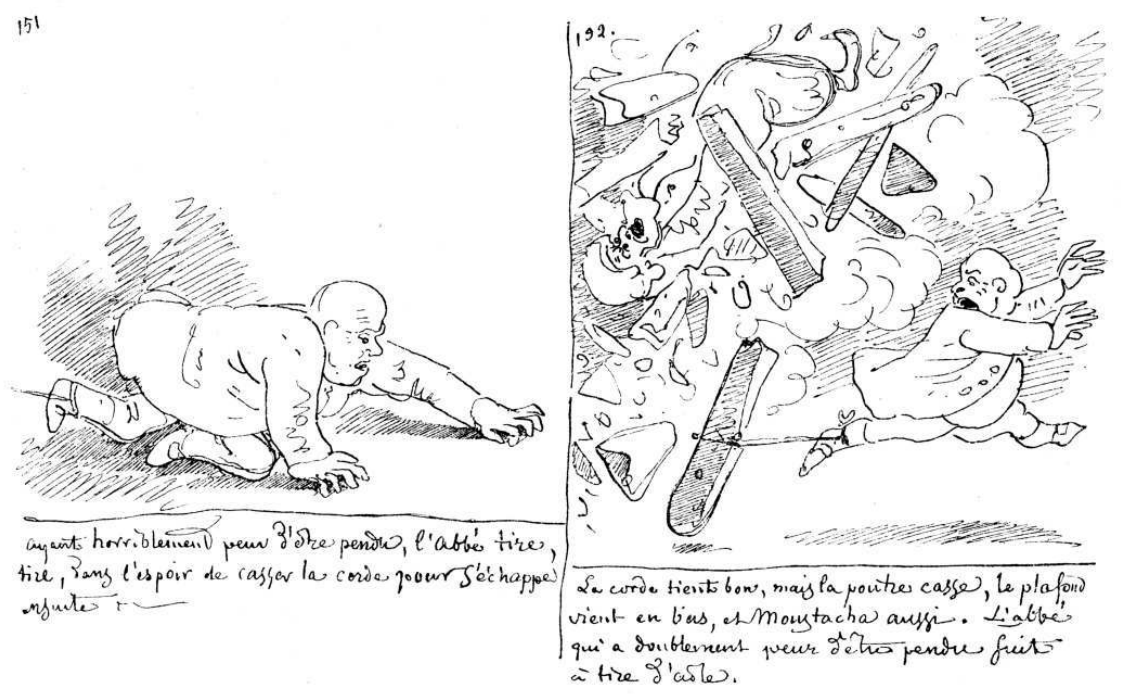

Fig. 9
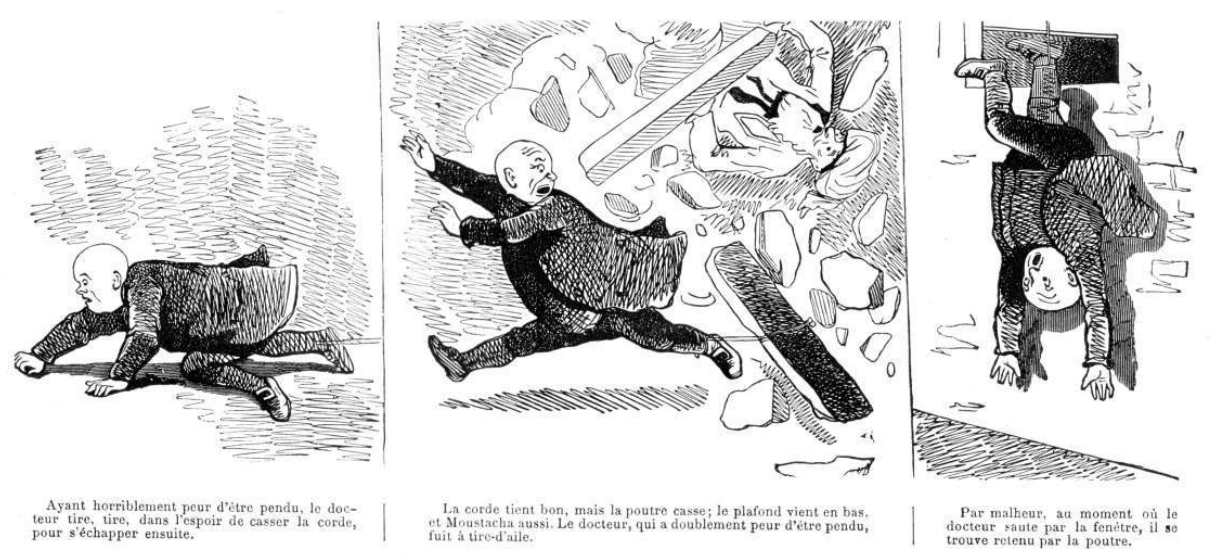

12

Fig. 7 à 9 : Histoire de Monsieur Cryptogame, troisième version par Cham, 1845

6 Enfin, chez Monsieur Crépin (1837), l'interaction des images disparait au profit aussi d'une meilleure lisibilité : trois images sur quatre dans la première version inédite étaient des plans d'ensemble. Toujours chez Monsieur Crépin, la fameuse scène du "Tâter crânien » passe de six images par planche à deux dans la seconde version publiée, laissant tomber l'emboîtement des cadres mais amplifiant du coup la dimension très théâtrale. Si Töpffer abandonne ce système - très en avance sur son temps - à deux strips superposés, quel peut donc en être la raison? Le lecteur n'aurait-il pas eu une idée à la fois plus globale, plus vivante et plus animée de la scène où le personnage jouait et décomposait son mouvement plus longtemps? L'effet de mime était redoublé. Les images se renvoyaient 
les unes aux autres et le regard du lecteur empruntait des chemins obliques et pas uniquement latéraux. La superposition des registres permettait en effet de jouer des diagonales et donc de dramatiser, de dynamiser le récit. Cette lecture impliquait-elle un effort de déchiffrement des images (en l'occurrence de gauche à droite puis de haut en bas) que l'inventeur aurait jugé trop important à l'époque pour un lecteur encore vierge de toute habitude en la matière? Il se trouve que Töpffer avait déjà expérimenté la planche à plusieurs registres, et c'est de manière plutôt inattendue dans ses carnets de voyage que cela se joue.

7 Cette planche (fig. 10), extraite de Voyage entre deux eaux, 1829, et réalisée au lavis d'encre de Chine, met en scène plusieurs personnages et la répétition de l'un d'entre eux, Monsieur Delaplanche (sic!), permet de parler véritablement de planche et de narration. Or que raconte-t-elle? Une scène de brouillard, de glissade. Une scène de confusion. Dans l'esprit de Töpffer, une telle planche qui superpose les rangées d'images (ici jusqu'à trois) est associée à l'idée de chaos. Avançons plus loin, dans le travail largement méconnu de Töpffer sur ses carnets de voyage. Comment est-il venu au carnet comme forme définitive, qui n'existait pas ou marginalement avant lui ?

Fig. 10

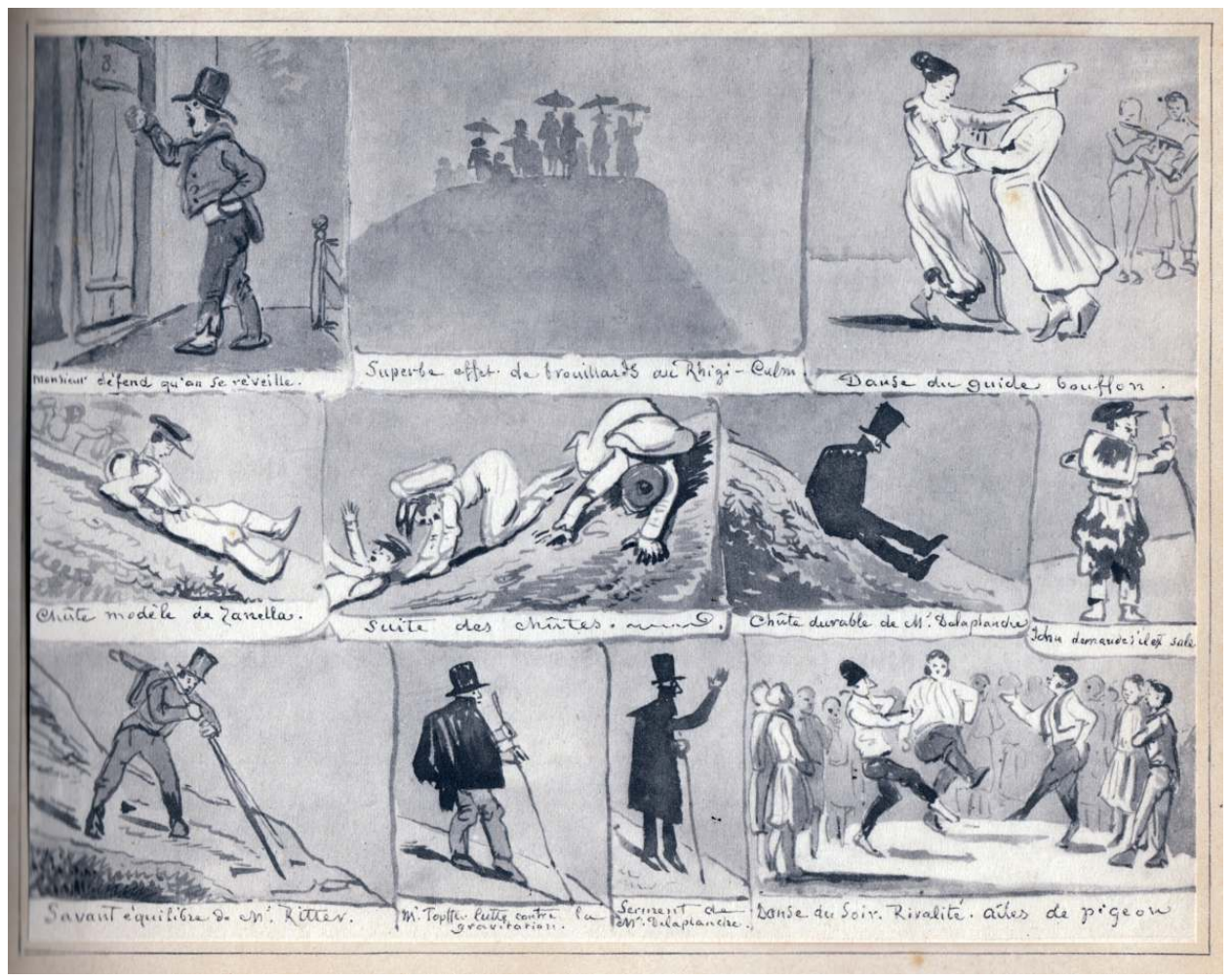

Fig. 10 : Voyage entre deux eaux, 1829

\section{Sterne avant Töpffer}

Dans le Voyage sentimental que fait l'Anglais Sterne en France et en Italie en 1765, et dont il tire un texte (sans dessin mais dont de nombreuses rééditions seront illustrées) d'une saveur subtilement ironique, l'auteur déroule une vision très personnelle des lieux qu'il traverse et de rencontres aussi charmantes qu'éphémères. Sterne se démarque par là des 
autres récits de voyage qui foisonnèrent dans cette seconde moitié du XVIII ${ }^{\mathrm{e}}$ siècle et qui avaient plutôt pour ambition une certaine objectivité dans les descriptions de pays et de villes alors encore largement méconnus. Mais ce qui va probablement influencer Töpffer est l'attitude de Sterne au cours de ce voyage autobiographique : même s'il connaît sa destination, il se livre en chemin aux flâneries et au plaisir des rencontres imprévues. Prémices du zigzag?

\section{Le carnet de voyage avant la bande dessinée}

Rodolphe Töpffer, inventeur en 1827 de la littérature en estampes qui deviendra la bande dessinée, reprend ce faisant un format à l'italienne qu'il a déjà éprouvé par l'entremise d'au moins deux carnets de voyage. S'agit-il d'un simple souci de cohérence éditoriale ? Töpffer représente le zigzag de plusieurs façons: zigzag des lignes de crête des montagnes alpines, zigzag des flots secouant en tous sens le frêle esquif qui le transporte avec ses élèves, zigzag des sentiers qui serpentent le long des pentes pour en atténuer le côté abrupt.

Fig. 11

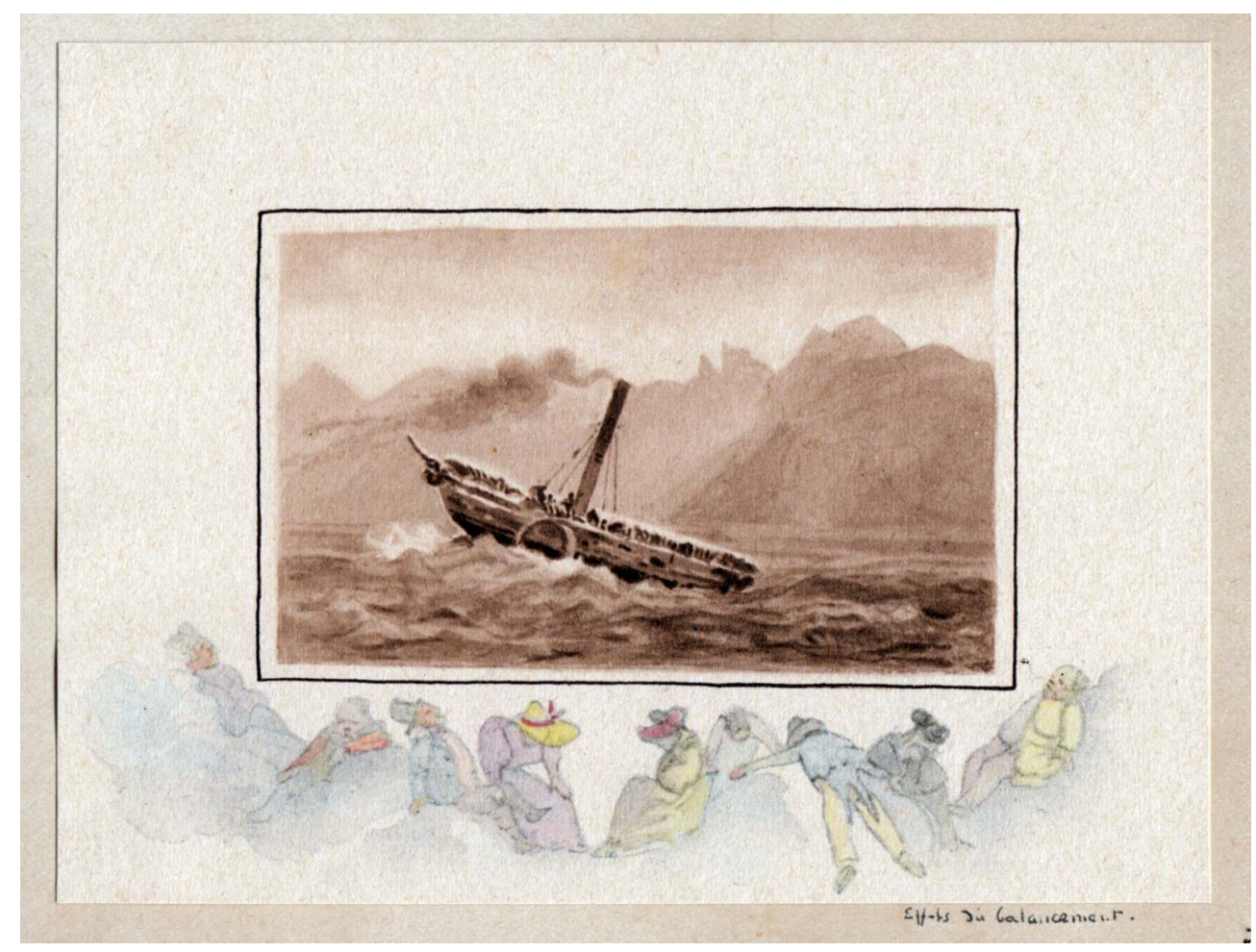

Fig. 11 : Effets du balancement, hors-texte de Voyage entre deux eaux, inédit (1829), première édition du Journal de Genève en 1943 
Fig. 12

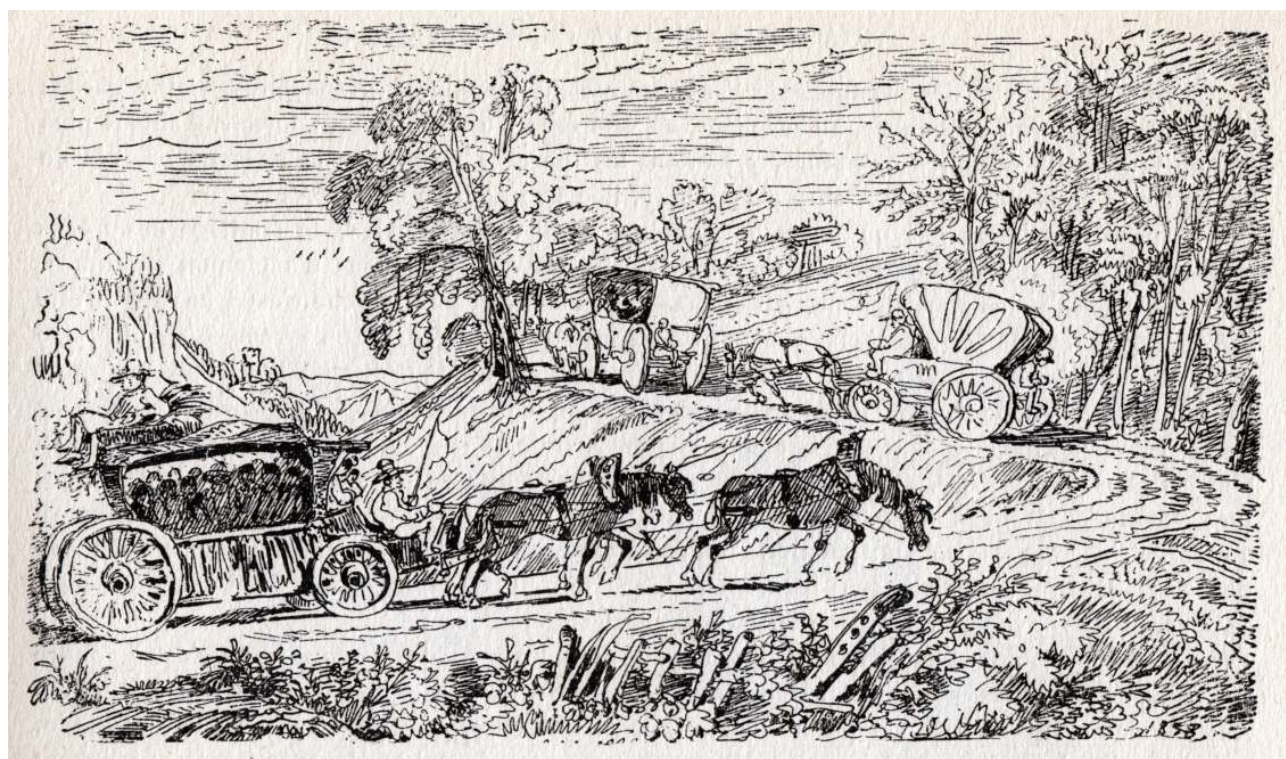

Fig. 12 : In-texte de Voyage à la Grande chartreuse (1833), réédition chez Boissonas (1922)

10 Il est une autre forme qui peut s'apparenter au zigzag : les allers-retours que fait l'auteur entre des scènes intérieures et extérieures; entre les espaces étroits, petits et sombres des auberges la nuit, lieux de pénombre où les personnages sont souvent « aveugles » ou somnambules d'une part et les vastes panoramas des montagnes vertigineuses, des glaciers éblouissants de lumière qui s'offrent aux yeux de l'équipée d'autre part.

Fig. 13

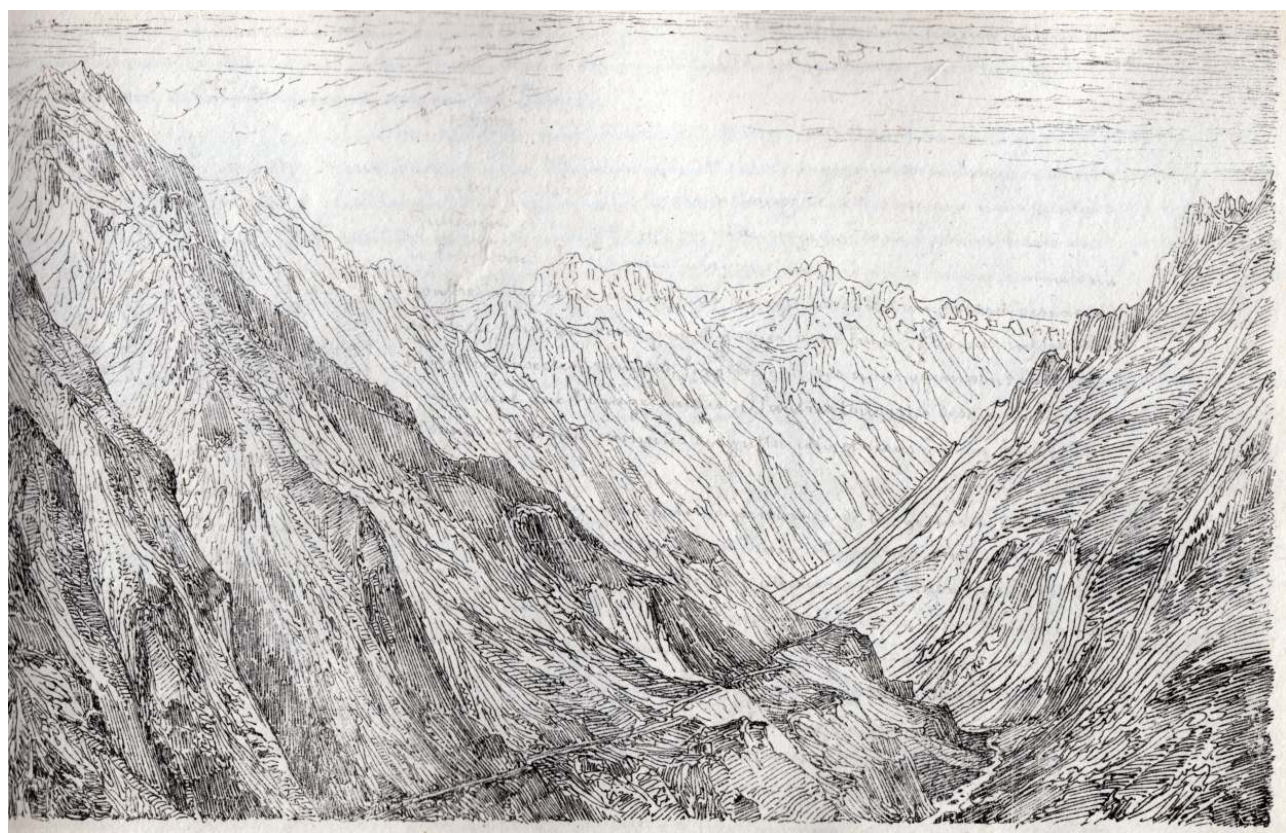

Fig. 13 : Page 55 de Voyage en zigzag par monts et par vaux, EO, 1836

11 La tension qui s'établit entre ces petits in-textes et ces hors-textes pleine page est frappante et constitue une sorte de pulsation narrative qui scande le récit. 

d'article), annoncent l'humour et son goût déterminé pour l'anecdote: ainsi le Voyage aquatico-historico-romantico-comico-comique dans le nord-est (1826), ou bien le Voyage en Italie à la poursuite d'un passeport (1828) et encore le Voyage entre deux eaux (1829), à l'époque même où Töpffer invente presque simultanément la littérature en estampes. Ces titres vantent, chacun à leur gré, le charme profond des étapes imprévues, des rencontres saugrenues, des incidents de parcours et d'étape qui font les voyages vrais. Jusqu'à celui qui s'imprimera dans les mémoires grâce à son titre fabuleux : Voyage en zigzag par monts et par vaux en 1836 .

La fortune de ce titre réapparaît dans Voyages en zigzag et Nouveaux Voyages en zigzag, au pluriel, puisqu'ils reprennent le premier cinq et le second trois voyages du professeur (fig. 15). Ils ne seront que des compilations éditoriales et selon moi des trahisons visuelles, mais c'est par elles et leurs innombrables rééditions que Töpffer accédera à la postérité. "Les grandes scènes de la Suisse ont été abandonnées jusqu'ici aux profanations des colorieurs ", regrettait déjà Töpffer à son époque. Avant que ses dessins légers et spontanés ne se voient outragés à leur tour par le "lest graphique " des graveurs, qui interprètent pesamment son travail dans ces éditions tardives des Voyages en zigzag; le premier paraît en 1844, deux ans avant la disparition de Rodolphe Töpffer emporté par une maladie des yeux et de la rate à 47 ans, et le second est posthume.

Fig. 14

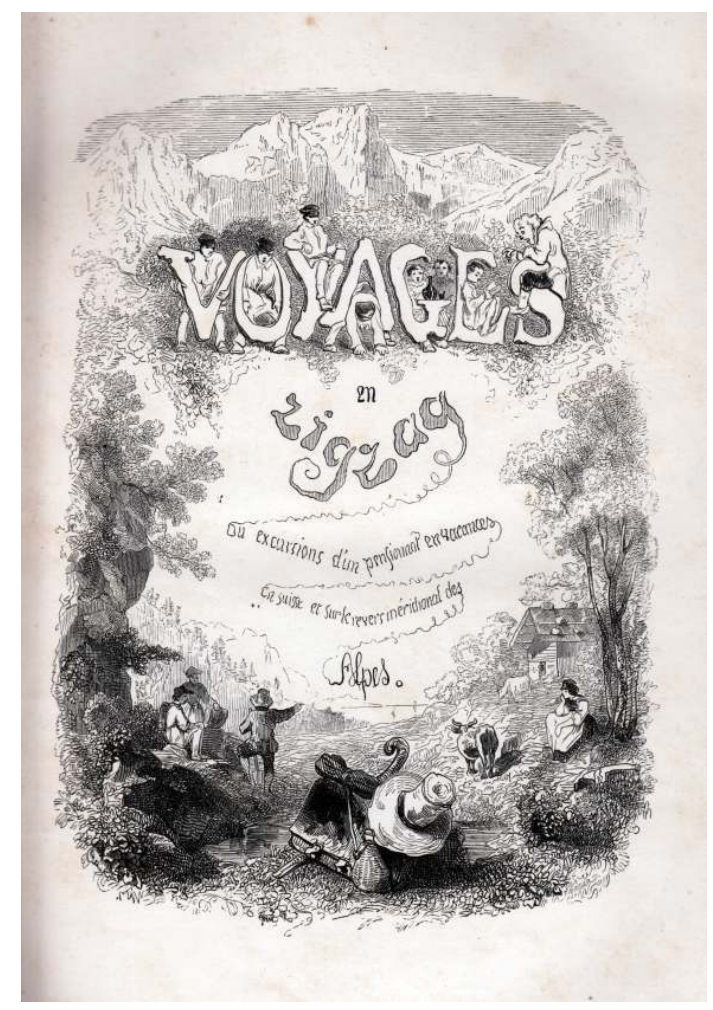

Fig. 14 : Page de titre de Voyages en zigzag par monts et par vaux $(E 0,1836)$ 
Fig. 15

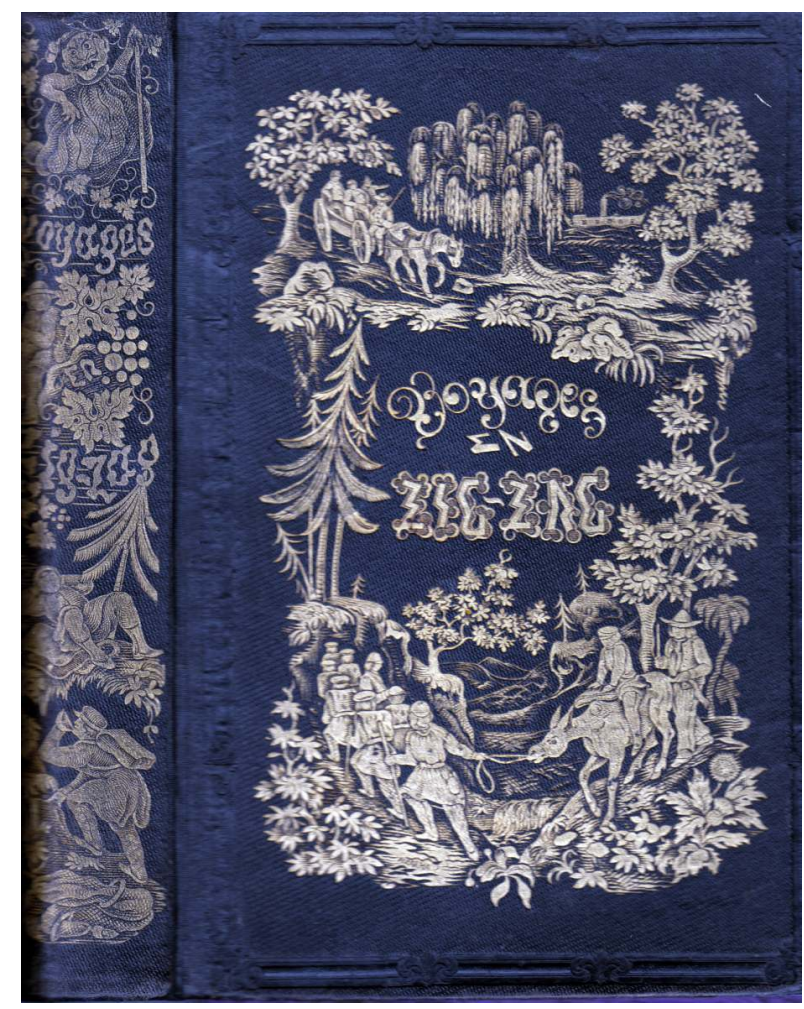

Fig. 15 : Page frontispice et percaline gravée de couverture de Nouveaux Voyages en zigzag (éditions Garnier, 1850)

14 Il existe enfin un motif de zigzag présent... au cœur de son trait: la plume de Töpffer gratte et griffe le papier en allers-retours nerveux qui font vibrer le dessin, en particulier dans le traitement des ombres.

15 Rodolphe définit lui-même son trait par des « bonds de plume ${ }^{4} »$. 


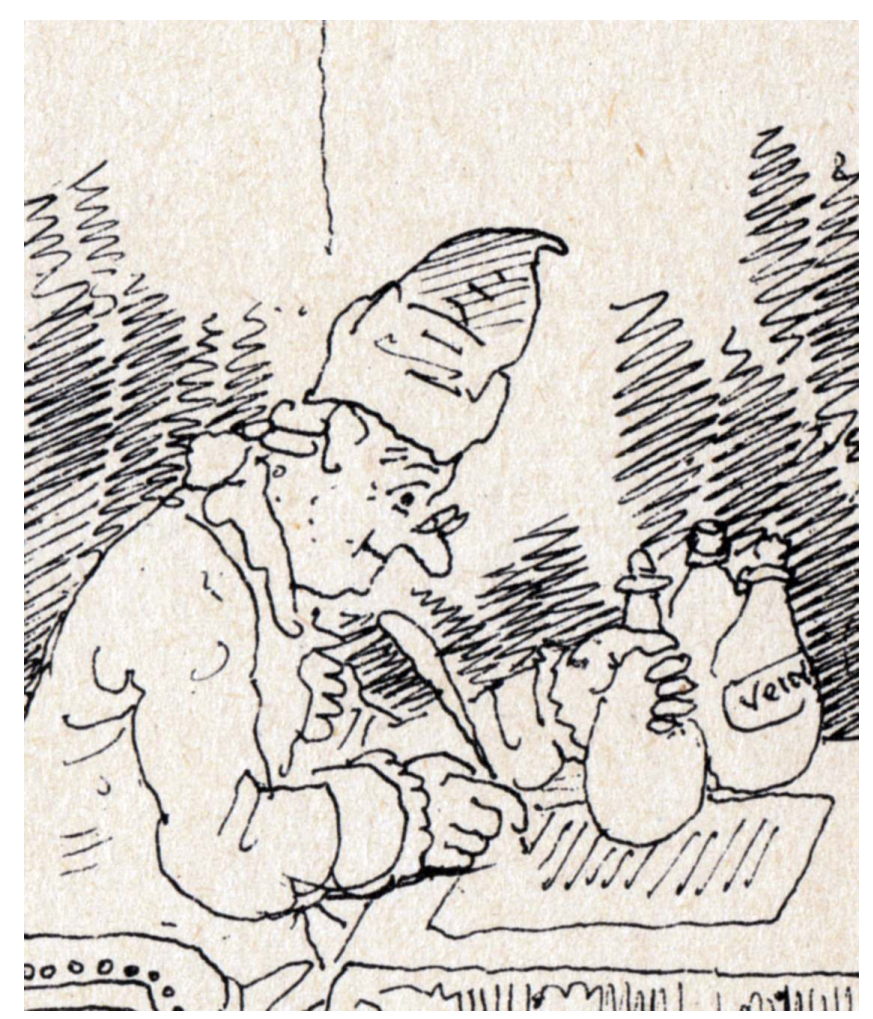

Fig. 16 : Extrait de la page 7 de Monsieur Pencil (1840)

Cette spontanéité du zigzag graphique va de pair, dans les carnets de voyage comme dans les histoires en estampes, dans des dominantes opposées, avec le choix affirmé d'une cohabitation visuelle singulière qui va caractériser le style de Töpffer : l'intrication entre texte manuscrit, écriture cursive et croquis légers, à l'aspect délibérément inachevé. Il écrit encore ${ }^{5}$ (fig. 17) :

Le sentiment qui trouve est plus heureux que le savoir qui imite; la brusquerie qui fait violence aux formes tout en enjambant les détails sert mieux la verve que l'habileté circonspecte qui courtise les formes en se marquant dans les détails ; enfin, dans les sujets plaisants surtout, ou de folle fantaisie, une ânerie audacieuse qui saute un peu brutalement sur l'idée qu'elle a en vue, au risque d'omettre quelques traits et de briser quelques formes, a le plus souvent mieux atteint le but qu'un talent plus exercé, mais plus timide, qui s'y dirige lentement au travers de tous les méandres d'une exécution élégante et d'une imitation fidèle...

Fig. 17

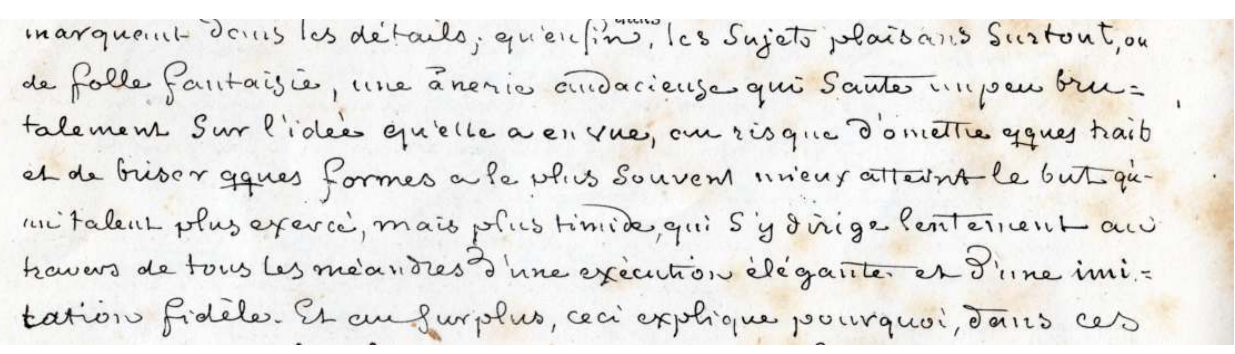

Fig. 17 : Extrait de la page 8 de Essai de physiognomonie (autographié à Genève, 1845) 


\section{Dans les pas de Töpffer}

17 Mettons pour un moment nos pas dans ceux de Töpffer (qui n'en demandait pas tant) et échafaudons les hypothèses quant aux conditions de sa création. Le sentier grimpe mais les haltes sont fréquentes car l'équipage est jeune et inexpérimenté : une douzaine de moussaillons attachants et curieux avec lesquels il se plaît à herboriser dans cette pratique rousseauiste qui encourage le contact au plus près de la nature. Töpffer avait lu Rousseau, né lui aussi à Genève et ayant résidé en Savoie une quinzaine d'années avant de se rendre à Paris. Les Rêveries du promeneur solitaire (1776-1778), se composent de chapitres que Rousseau nomme « Promenades».

Pour Töpffer entouré de ses pensionnaires, l'organisation des couches rocheuses, les variétés d'arbres, les espèces de plantes ou de fleurs sauvages, tout est prétexte à commentaire. L'apprentissage du terrain. Sans oublier les pratiques locales : il s'attarde auprès des scieurs de long, des bergers, des paysans. La prochaine halte sera un moment de contemplation privée dédiée au dessin, à la manière de la cinquième promenade de Rousseau qui y fait l'éloge du lâcher-prise avant la lettre et de la méditation. La durée de la pause est celle de la réalisation du dessin, face au spectacle du lieu, torrent de montagne, cirque raviné de précipices ou modeste épave de bateau pourrissante. Moment de suspension de la pensée, de la plongée dans d'autres abîmes: ceux, virtuels, qui libèrent le professeur de ses ouailles, lui offrant à son tour une rare récréation. Récréation créative. Töpffer scrute, trace, scrute et trace encore.

19 Un nouveau hors-texte. Il faut déjà repartir vers le col, vers l'auberge où se mitonne le souper réparateur.

20 Tout le monde ira se coucher tôt, trouver «le délicieux sommeil ${ }^{6}$ » avant les menus incidents de la nuit, somnambulisme ou lits trop courts.

21 Les in-textes du carnet seront réalisés plus tard, au retour chez lui, au stade de la composition du livre, en ajustant judicieusement la balance entre envolées savoureuses de texte, dessins de petit format et dessins pleine page qui ont été exécutés devant le spectacle des panoramas montagneux. 
Fig. 18

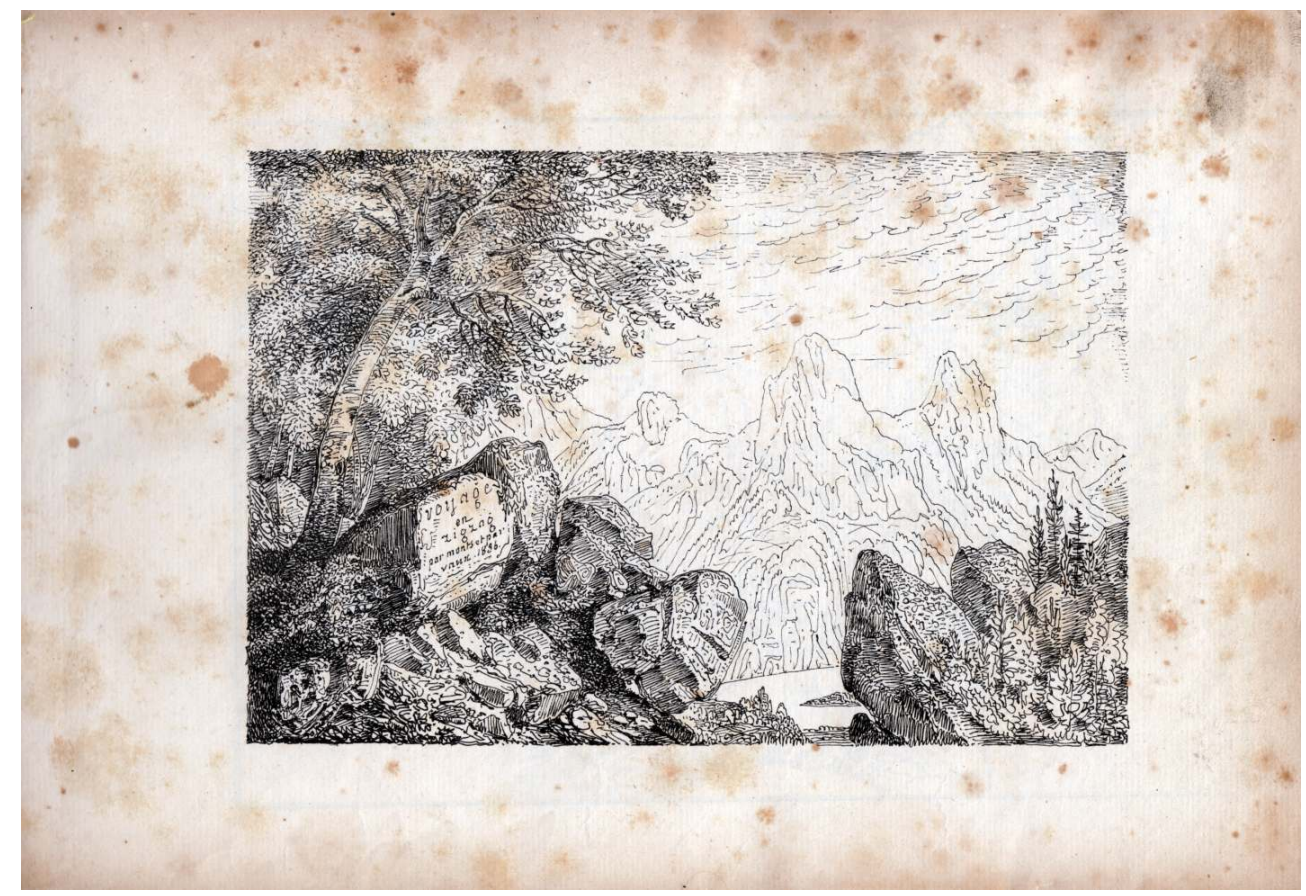

Fig. 18: Page de titre de Voyage en zigzag par monts et par vaux $(E 0,1836)$

C'est le moment de la réminiscence, quand l'auteur se rappelle les anecdotes éphémères, les rencontres avec les Savoyards, le moment où tous les souvenirs se bousculent dans sa tête jusqu'à déborder sur le papier vers le récit. Ces trois unités töpfferiennes - écriture manuscrite, hors-textes, in-textes - dialoguent parfaitement, pour une raison bien précise qui a été minorée jusque-là : l'absence fréquente et délibérée de cadres isolant les images du texte. La matière graphique épouse les linéaments de l'écrit. Ce choix formel est contraire aux histoires en estampes au sein desquelles l'auteur se plait à redoubler les séparations jusqu'à emboîter les cadres, détourer les textes sous l'image en contournant même les pattes des lettres (fig. 19). 
Fig. 19

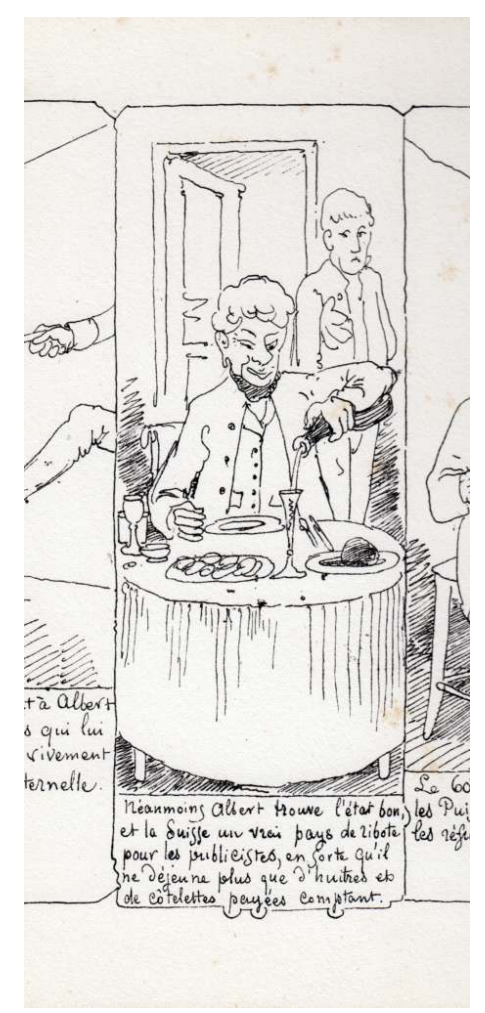

Fig. 19 : Exemple de détourage des lettres du texte, Histoire d(Albert (Paris, Caillet, 1860)

Fig. 20

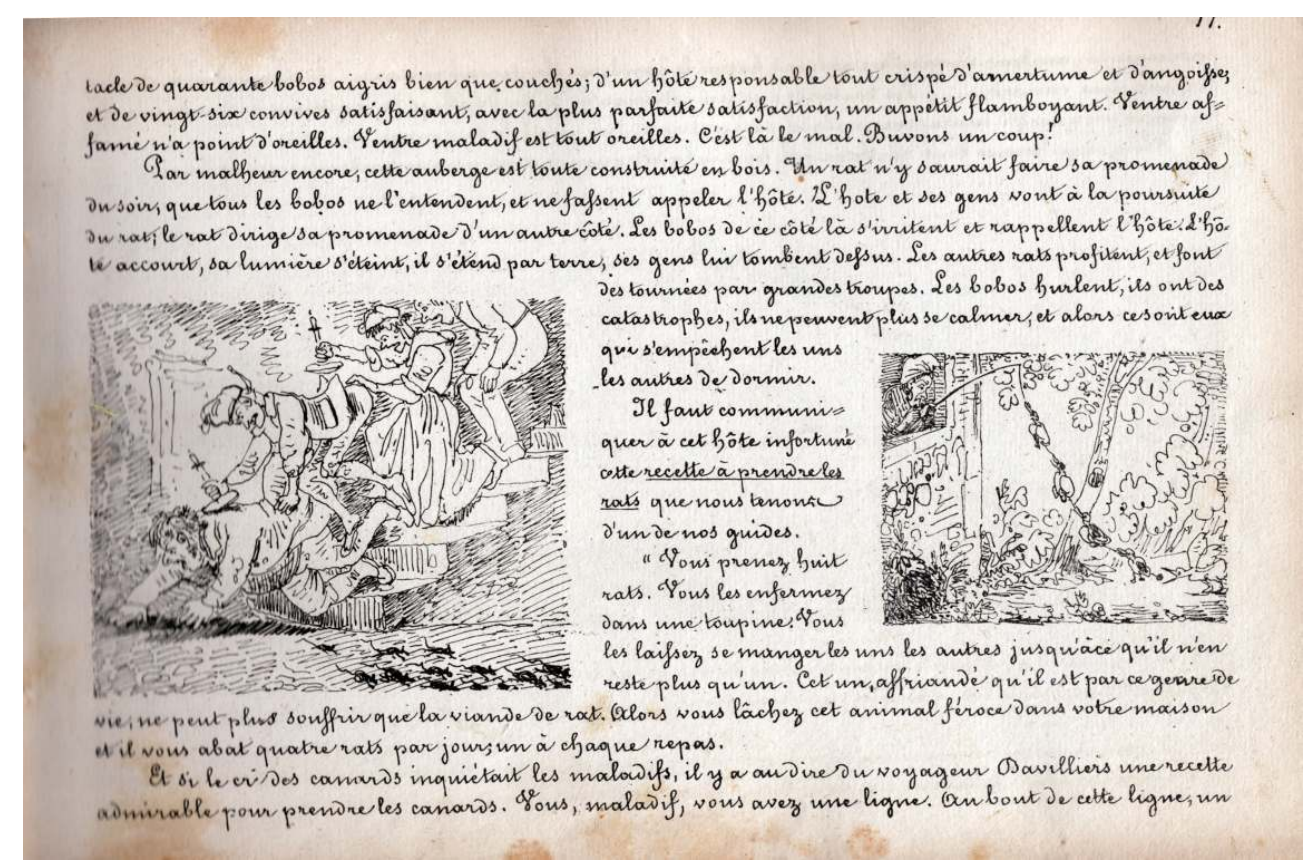

Fig. 20 : Voyages en zigzag par monts et par vaux (EO, 1836, p. 11)

Il y a quelque chose d'étrange dans le trait de Töpffer, qui peut échapper à l'attention dans le flux très fluide de la lecture. Le trait change fréquemment de direction, prenant 
souvent un tour comique au gré de ses inflexions. Je ne trouve pas mieux que « cabossé " pour qualifier un tel trait. La dimension enfantine inhérente au terme va de pair avec l'aspect léger et spontané cultivé par Töpffer. Cabossé, à la manière de quelqu'un qui écrirait ou dessinerait en progressant sur un chemin pierreux. Le cahot encore, au détriment de la glissade horizontale que pourrait procurer... le chemin de fer, que justement il détestait!

Nul doute selon moi que Töpffer a conçu ses sept histoires en estampes sur les chemins de montagne. La marche est féconde pour l'esprit, le fait est bien connu de tous les concepteurs de récits. Le corps marche "de son côté », et du sien, le cerveau se met en quelque sorte en roue libre, prêt à toutes les associations d'idées, à toutes les bifurcations, à l'irruption des souvenirs aussi, hors du raisonnement réflexif. La pensée prend les chemins de traverse de la rationalité. L'attention se fixe sur l'environnement pour mieux s'échapper vers des territoires inconnus, des idées inattendues.

La méditation fait alors émerger les débuts d'histoire par des mises en situation: Vieuxbois avec un Objet aimé qui enfle et maigrit à tour de rôle, Crépin avec ses onze enfants (réflexivité de Töpffer et ses élèves ?), Pencil en prise avec les caprices du vent, Festus se trompant de chambre ou bien Cryptogame chassant les papillons.

\section{Bandes sans zigzag}

Revenons à la forme de ces histoires en estampes. Alors que Rodolphe Töpffer fait le plaidoyer du zigzag dans vingt-cinq carnets, pourquoi abandonne-t-il la lecture en $\mathrm{Z}$ qu'il avait découverte dans la planche de bande dessinée (avant la lettre) ? Entre 1827 et 1844, Rodolphe écrit, dessine et autographie sept histoires. Viennent, successivement et par dates de création : Les Amours de Monsieur Vieuxbois (1827), Le Docteur Festus (1829), Histoire de Monsieur Cryptogame (1830), Histoire de Monsieur Jabot (1831), Monsieur Crépin (1837), Monsieur Pencil (1831), et Histoire d'Albert (1844). Ils seront autographiés dans un ordre différent. Vieuxbois est l'amoureux transi de l'objet aimé qu'il poursuit aveuglément en fonçant droit devant lui. Jabot le vaniteux se casse la figure (p.11). Ses apparitions successives, tout comme celles de Vieuxbois ou Cryptogame, sont alignées peu ou prou selon une horizontale qui renforce les effets burlesques de pantomime. Crépin et Pencil sont des peudo-savants typiques du XIX ${ }^{e}$ qui s'aveuglent dans leurs lubies et Albert s'engage dans la politique pour aboutir à une guerre civile. C'est un inadapté qui ne parvient pas à garder le moindre métier. Cryptogame détale à l'horizontale devant une Elvire insistante. Les personnages foncent tout droit latéralement dans le plan de la page, de gauche à droite ou de droite à gauche, jamais dans la profondeur de l'image. Or quel autre dispositif peut mieux servir de telles mises en scène si ce n'est une suite d'images horizontales qui font filer fatalement la narration de gauche à droite et renforcent le caractère d'accélération aveugle?

En $2010^{7}$, je suggérais que la raison pour laquelle Töpffer choisit en fin de compte la planche à registre unique de séquence était une sorte de prudence, souhaitant limiter la densité de la page et le nombre d'images présentes sous l'œil du lecteur. Töpffer, s'il n'était pas un adepte du progrès sur le plan technique, avait conscience d'inventer une nouvelle forme de littérature. Une hypothèse, plus excitante, a émergé récemment à la suite d'une de ces discussions passionnées auxquelles Thierry Smolderen et moi aimons nous livrer, et qui nous placent rapidement dans un espace virtuel non localisé. L'idée 
serait la suivante : si Töpffer a choisi le récit à un seul registre, c'est bien pour dénoncer la ligne droite, autrement dit la conduite, bêtement obtuse de l'homme qui fonce tête baissée droit devant lui, n'ayant cure des chemins de traverse, des errances qui certes font perdre du temps mais réservent bien des découvertes à la faveur d'un parcours en zigzag, seul digne de louange et d'apprentissage de soi et pour soi : les livres en zigzag ne sont-ils pas des récits de découverte et d'éducation? Qui musarde s'enrichit. Poussant la logique de la ligne droite dans ses extrémités, c'est bien à une ironie moqueuse que se livre Töpffer. Il raille les trajets directs et les comportements à œillères. Tous les personnages qui évoluent dans cette forme horizontale de narration et courent obstinément en faisant le grand écart sont des personnages qui se trompent. Ils ont « tout faux », tout comme les chevaux qui galopent les pattes écartées, et que d'ailleurs Töpffer reprend, dans les peintures de chasses $\mathrm{du}_{\mathrm{XVIII}}{ }^{\mathrm{e}}$ d'avant la photographie. Jusque dans la forme, dans son trait même, la ligne droite est définitivement étrangère à son style graphique, cultivant le dessin tremblé, interrompu, à l'instar de l'écriture manuscrite.

Töpffer sème loin et ses trouvailles germent encore de nos jours : c'est la bande dessinée contemporaine qui fait le pont entre le carnet en zigzag et la BD qui accélère la lecture de gauche à droite, de Claire Brétécher à Joann Sfar. Les planches des auteurs d'aujourd'hui reposent très souvent sur une construction composée en $\mathrm{Z}$, selon le parcours du regard qui lit une planche. En outre, les essais sur et avec la bande dessinée sont appelés à se développer; ils retrouveront cette forme vivante de l'association visuelle entre écriture libre et dessin, tracés du même instrument. C'est là finalement qu'apparaît le génie radical de Töpffer et le chaînon manquant qui nous permet de relier ses deux inventions, génitrices de bientôt deux siècles de création graphique et narrative et de milliards de livres édités. Carnets de voyage et albums de bande dessinée ne sont pas près de déserter les librairies. Le carnet de voyage de Töpffer approfondit le goût pour la digression et la flânerie narrative initiées par Sterne en littérature, tandis que ses «bandes dessinées " vilipendent l'aveuglement de la ligne droite.

Soient, sauf erreur, vingt-quatre carnets de voyage, dont quatorze autographiés.

\section{BIBLIOGRAPHIE}

\section{Carnets de voyage originaux (manuscrits avec dessins contrecollés) ou autographiés (mention)}

- Voyage pittoresque dédié à Madame Töpffer, 1825

- Voyage aquatico-historico-romantico-comico-comique dans le nord-est, 1826 (édité pour la première fois en 1937)

- Voyage dans les Alpes, 1826

- Voyage autour du Lac de Genève, 1827

- Voyage de 1828 (non illustré) 
- Voyage en Italie à la poursuite d'un passeport, 1828 (édité pour la première fois en 1941)

- Voyage entre deux eaux, 1829 (édité pour la première fois en 1943)

- Voyage à Chamonix, 1830

- Voyage à Turin, 1830 (édité pour la première fois en 1935)

- Voyage de 1831

\section{Carnets de voyage autographiés}

- Voyage dans l'Oberland bernois, 1827

- Excursion dans les Alpes, 1832

- Voyage dans la Grande chartreuse, 1833 (réédité en 1922)

- Voyage à Milan, 1833

- Voyage à la Grande chartreuse, 1833

- Voyage à Gênes, 1834 (recomposé en 1843 par RT pour l'édition des Nouveaux Voyages en zigzag, Lecou Paris, 1854)

- Chamonix, 1835

- Voyage en zigzag par monts et par vaux, 1836

- Voyage en zigzag (Saint Gothard), 1838

- Voyage de 1839, Milan, Côme, Splügen

- Voyage de 1840, Chamonix, l'oberland, le Righi

- Le Tour du Lac en 4 journées, 1841

- Voyage à Venise, 1841

- Voyage autour du Mont-Blanc dans les vallées d'Herons, de Zermatt et au Grimsel, 1843

\section{Éditions aux dessins interprétés par d'autres graveurs et imprimés en typographie}

- Voyages en zigzag, éditions Dubochet, Paris, 1844

- Nouveaux Voyages en zigzag, éditions Lecou, Paris, 1854

\section{NOTES}

1. Je reprends ici pour la démonstration un paragraphe de mon livre paru en 2010 (Créer une BD, Paris, Éditions First, coll. « Pour les nuls », 2010).

2. Benoît Peeters, Case, planche, récit, Paris, Casterman, 1991 ; revu en 1998.

3. On pense également à Tristram Shandy, antérieur au Voyage sentimental, où se rencontre déjà la fameuse page des zigzags.

4. Essais de physiognomonie, autographié à Genève, 1845, p. 13.

5. Ibid.

6. Voyage en Italie à la poursuite d'un passeport, 1828.

7. Créer une BD, op. cit. 


\section{AUTEUR}

GÉRALD GORRIDGE

fr 